\title{
Histopathological audit of renal biopsy in Nepalese children: two-center experience
}

\author{
Shrestha Devendra ${ }^{1}$, Dhakal Ajaya Kumar ${ }^{1}$, Basnet Nabin Bahadur ${ }^{2}$, KC \\ Shiva Raj ${ }^{3}$, Kafle Rishi Kumar ${ }^{2}$
}

${ }^{I}$ Department of Pediatrics, KIST Medical College and Teaching Hospital, Lalitpur, Nepal ${ }^{2}$ Department of Nephrology, Sumeru Kidney Hospital, Lalitpur, Nepal

${ }^{3}$ Department of Pathology, KIST Medical College and Teaching Hospital, Lalitpur, Nepal

\section{Keywords:}

Hematuria;

Histopathology;

IgA nephropathy;

Kidney;

Nephrotic;

Renal

\begin{abstract}
Background: Renal biopsy is an invaluable tool which provides histopathological description of renal disease in terms of severity of lesion and helps in formulating the long term plan. However such studies with histopathological description of renal biopsy among Nepalese children are scarce.

Material and Methods: This was a retrospective study conducted among all children aged less than 18 years who underwent renal biopsy at two tertiary centers in Nepal between July 2015 and December 2017.

Results: All 72 renal biopsies were done with Bard 18G spring loaded gun. Nephrotic syndrome and mixed nephritic-nephrotic features were the commonest indications for renal biopsy. IgA nephropathy was the most frequent histopathological diagnosis $(20.8 \%)$ which was mainly observed in children of age group 11-18 years followed by minimal change disease (16.7\%) and diffuse proliferative glomerulonephritis (16.7\%). Majority of children with recurrent gross hematuria (6/7) or mixed nephritic-nephrotic features $(6 / 8)$ had IgA nephropathy. Focal segmental glomerulosclerosis (6/8) was commonest in children with steroid resistant nephrotic syndrome and nephrotic syndrome with atypical features. Majority of children $(10 / 12)$ with diffuse proliferative glomerulonephritis had features of poststreptococcal glomerulonephritis and 6/12 had crescents in glomeruli. Lupus nephritis (13.9\%) was the commonest secondary cause of glomerular pathology and was observed predominantly in 11-18 years age.

Conclusion: Renal biopsy is safe and not associated with clinically significant complications. Nephrotic syndrome was the commonest indication for renal biopsy and minimal change disease predominated. IgA nephropathy was the commonest histological diagnosis overall, as well as in children who presented with recurrent gross hematuria or mixed nephritic-nephrotic features.
\end{abstract}

Correspondence:

Dr. Devendra Shrestha, MD, Fellowship in Pediatric Nephrology

Associate Professor, Department of Pediatrics,

KIST Medical College and Teaching Hospital, Lalitpur, Nepal

Email: devendra.shrestha@gmail.com

ORCID ID: 0000-0002-3661-2274

Received : January $18^{\text {th }} 2018 ;$ Accepted : February $26^{\text {th }} 2018$; Published : March $21^{\text {1st }} 2018$

Citation: Shrestha D, Dhakal AK, Basnet NB, KC Shiva Raj, Kafle RK. Histopathological audit of renal biopsy in Nepalese children: two center experience. J Pathol Nep 2018;18:1244-50. Doi: 10.3126/jpn.v8i1.19443

Copyright: This is an open-access article distributed under the terms of the Creative Commons Attribution 4.0 International License, which permits unrestricted use, distribution, and reproduction in any medium, provided the original author and source are credited.

\section{INTRODUCTION}

Renal diseases are important cause of pediatric hospital admissions and constitute $6.9 \%$ of annual pediatric admissions in Eastern Nepal. ${ }^{1}$ Glomerular diseases are the most prevalent renal diseases ${ }^{1}$ and cause significant morbidity and mortality. Many children with renal disease do not require renal biopsy for their diagnosis. However, in some patients, renal biopsy remains an indispensable tool for establishing histological diagnosis, ascertaining severity of disease, planning and monitoring of treatment modality as well as prognosticating the disease. Nephrotic syndrome with steroid resistance, steroid dependence or 
Table 1. Indications for renal biopsy

\begin{tabular}{|c|c|}
\hline Indications & Number $(\%)$ \\
\hline Nephrotic syndrome & $25(34.7)$ \\
\hline $\begin{array}{l}\text { SRNS }=8 \\
\text { SDNS }=8 \\
\text { FRNS }=2 \\
\text { Age related }=4 \\
\text { Positive ANA = 1 } \\
\text { Acute kidney injury=1 } \\
\text { Persistent microscopic hematuria=1 }\end{array}$ & \\
\hline Mixed nephritic-nephrotic features & $20(27.8)$ \\
\hline $\begin{array}{l}\text { Urinary abnormalities with systemic features } \\
\mathrm{SLE}=9 \\
\mathrm{HSP}=4\end{array}$ & $13(18.1)$ \\
\hline Gross hematuria & $8(11.1)$ \\
\hline $\begin{array}{l}\text { Acute glomerulonephritis with rapidly } \\
\text { deteriorating renal function }\end{array}$ & $6(8.3)$ \\
\hline Total & 72 (100) \\
\hline
\end{tabular}

with atypical features, recurrent gross hematuria, staging of systemic lupus erythematous (SLE) nephritis and Henoch Schonlein purpura (HSP) nephritis and unexplained acute kidney injury (AKI) are few of indications for performing renal biopsy in children.

The knowledge of pattern of renal disease and histopathological association to presenting features in a specific region is of importance to practitioners as they have been shown to be different in various centers and geographical locations..$^{2-7}$

There is a relative lack of data regarding prevalence of glomerular diseases in children with their association to histopathological picture in Nepalese children. Therefore this study was conducted to describe pattern of glomerular diseases in different age groups, indications for renal biopsy as well as their histopathological appearance.

\section{MATERIALS AND METHODS}

This was a retrospective study of children aged less than 18 years who underwent percutaneous renal biopsy between July 2015 and December 2017 at two tertiary care centers in Lalitpur, Nepal. Permission from the institutional review committee was obtained. Medical records of all the children who underwent renal biopsy were retrieved and data were analyzed. Those children with incomplete records or whose biopsy report was unavailable were not included in the study. Final data was analyzed only from children who had renal tissue in their histopathology reports.

Nephrotic syndrome was defined as children presenting with generalized edema, nephrotic range proteinuria $\left(>40 \mathrm{mg} / \mathrm{m}^{2} /\right.$ hour or spot urine protein creatinine ratio $>2$ ), hypoalbuminemia (serum albumin $3.5 \mathrm{mg} / \mathrm{dl}$ ) and hypercholesterolemia (serum total cholesterol $>200 \mathrm{mg}$ / dl). Steroid resistant nephrotic syndrome (SRNS) was defined as cases of nephrotic syndrome who did not achieve remission despite prednisolone at $2 \mathrm{mg} / \mathrm{kg} / \mathrm{day}$ for 4 weeks. Steroid dependent nephrotic syndrome (SDNS) was defined as cases of nephrotic syndrome who developed two consecutive relapses within two weeks of stoppage of steroid or on tapering doses of steroid. Frequently relapsing nephrotic syndrome (FRNS) was defined as cases of nephrotic syndrome that had 2 or more relapses in initial six months or more than 3 relapses in any one year period.

Acute glomerulonephritis (AGN) was defined as patient presenting with acute onset of edema, hematuria (gross or microscopic), oliguria, hypertension and azotemia.

Patients who had features of AGN and had nephrotic range proteinuria were categorized as mixed nephritic-nephrotic presentation.

Patients with two or more episodes of gross hematuria with or without proteinuria, edema or hypertension after exclusion of non-glomerular causes were classified as recurrent gross hematuria.

Patients presenting with rapidly deteriorating renal function (decrease in glomerular filtration rate by $50 \%$ as calculated by estimated glomerular filtration rate estimation using Schwartz equation) along with hypertension, edema and hematuria were defined as AGN with rapidly deteriorating renal functions.

Table 2. Histopathological appearance in nephrotic syndrome

\begin{tabular}{lcccc}
\hline & SRNS & SDNS & FRNS & Nephrotic syndrome with atypical features \\
\hline Minimal change disease & 2 & 6 & 1 & 2 \\
\hline Focal segmental glomerulosclerosis & 3 & 2 & 0 & 0 \\
\hline $\begin{array}{l}\text { Membranoproliferative } \\
\text { glomerulonephritis }\end{array}$ & 1 & 0 & 0 & 1 \\
\hline $\begin{array}{l}\text { Mesangioproliferative } \\
\text { glomerulonephritis }\end{array}$ & 0 & 0 & 0 & 0 \\
\hline Membranous nephropathy & 1 & 0 & 0 & 1 \\
\hline IgA nephropathy & 1 & 0 & 0 & 0 \\
\hline IgG nephropathy & 0 & 0 & 1 & 7 \\
\hline Total (n=25) & 8 & 8 & 2 & \\
\hline
\end{tabular}


Table 3. Age-wise histopathological appearance

\begin{tabular}{|c|c|c|c|c|}
\hline & 1-5 years & 6-10 years & $11-18$ years & Total \\
\hline IgA Nephropathy & 1 & 3 & 11 & 15 \\
\hline Minimal change disease & 3 & 3 & 6 & 12 \\
\hline $\begin{array}{l}\text { Diffuse proliferative } \\
\text { glomerulonephritis }\end{array}$ & 0 & 3 & 9 & 12 \\
\hline Lupus nephritis & 1 & 1 & 8 & 10 \\
\hline Focal segmental glomerulosclerosis & 3 & 1 & 4 & 8 \\
\hline $\begin{array}{l}\text { Mesangioproliferative } \\
\text { glomerulonephritis }\end{array}$ & 0 & 2 & 2 & 4 \\
\hline HSP nephritis & 0 & 1 & 3 & 4 \\
\hline $\begin{array}{l}\text { Membranoproliferative } \\
\text { glomerulonephritis }\end{array}$ & 0 & 0 & 2 & 2 \\
\hline Crescentic glomerulonephritis & 1 & 0 & 1 & 2 \\
\hline Membranous nephropathy & 0 & 0 & 1 & 1 \\
\hline IgG nephropathy & 0 & 0 & 1 & 1 \\
\hline Normal histology & 1 & 0 & 0 & 1 \\
\hline Total & 10 & 14 & 48 & 72 \\
\hline
\end{tabular}

Systemic lupus erythematosus was defined by fulfilling criteria as per American College of Rheumatology and those presenting with active urinary sediments were classified as lupus nephritis.

Patients with HSP (palpable purpura and renal involvement, abdominal pain and/or arthritis) along with gross hematuria or active urinary sediments or proteinuria or hypertension were classified as HSP nephritis.

Renal biopsy was indicated in children with steroid resistance nephrotic syndrome, before initiation of calcineurin inhibitors in SDNS or frequent relapses, age less than one year or more than 12 years, hypocomplementemia, persistent microscopic hematuria, sustained hypertension, acute kidney injury unattributable to hypovolemia or presence of systemic diseases. ${ }^{8}$ Similarly, recurrent gross hematuria, urinary abnormalities associated with systemic diseases (SLE or HSP) and unexplained AKI were other indications for renal biopsy.

Renal biopsies were performed under ultrasonography guidance with Bard 18G spring loaded gun. Local anesthesia or short intravenous sedation was given during procedure according to hospital protocol. Two cores of tissue were collected and each was sent for light microscopy and immunofluorescence study. Electron microscopy study was not done. Biopsy reports which included $\geq 10$ glomeruli were considered adequate for the study. ${ }^{9}$ Data analysis was done with SPSS17.0 and percentages and proportions of indications, histopathological diagnosis, demographic parameters and complications were calculated.

\section{RESULTS}

There were 76 biopsies, out of which 4 biopsies were excluded from study as there were insufficient renal tissue for histopathological analysis. There were 43 (59.7\%) males and $29(40.3 \%)$ females. The majority of children $(\mathrm{n}=48 ; 66.7 \%)$ were in age group 11-18 years, which was followed by $6-10$ years $(n=14 ; 19.4 \%)$ and $1-5$ years age group $(\mathrm{n}=10 ; 13.9 \%)$.

In the studied renal core biopsy specimens, median number of glomeruli were fifteen (range 2 -37). Adequate number of glomeruli i.e. $\geq 10$ was observed in 57 (79.2\%) biopsies. Four children (5.6\%) developed clinically significant post renal biopsy complications. One child developed clinically significant perirenal hematoma, gross hematuria and hypovolemic shock requiring blood transfusions who eventually recovered with conservative treatment. Three children had transient gross hematuria which subsided within first 24 hours. Five children had clinically insignificant subcapsular hematoma which resolved within two weeks.

The most common indication for performing renal biopsy was nephrotic syndrome $(\mathrm{n}=25 ; 34.7 \%)$ followed by mixed nephrotic nephritic features $(\mathrm{n}=20 ; 27.8 \%)$ and urinary abnormalities with systemic features $(\mathrm{n}=13 ; 18.1 \%)$. (Table 1)

Among the children with nephrotic syndrome, SRNS and SDNS were the most frequent indications observed in 8 $(11.1 \%)$ children each. Frequently relapsing variant was seen in $2(2.7 \%)$ of all the children. Nephrotic syndrome with atypical features were encountered in 7 (9.7\%) patients. Out of which 4 were of older age, 1 had positive antinuclear antibody (ANA), 1 presented with acute kidney injury (AKI) and 1 with persistent microscopic hematuria.

Among the patients with mixed nephritic nephrotic features $(n=20 ; 27.8 \%), 10$ patients $(13.9 \%)$ were clinically diagnosed clinically as poststreptococcal glomerulonephritis (PSGN) 
Table 4. Histological appearance in children in relation to indication for biopsy other than nephrotic syndrome

\begin{tabular}{|c|c|c|c|c|c|}
\hline & Gross hematuria & $\begin{array}{l}\text { Mixed nephritic- } \\
\text { nephrotic } \\
\text { features }\end{array}$ & $\begin{array}{c}\text { Acute } \\
\text { glomerulonephritis } \\
\text { with rapidly } \\
\text { deteriorating renal } \\
\text { function }\end{array}$ & $\begin{array}{c}\text { Urinary } \\
\text { abnormalities } \\
\text { with systemic } \\
\text { features }\end{array}$ & Total \\
\hline IgA Nephropathy & 6 & 6 & 1 & 0 & 13 \\
\hline $\begin{array}{l}\text { Diffuse proliferative } \\
\text { glomerulonephritis }\end{array}$ & 1 & 8 & 3 & 0 & 12 \\
\hline Lupus nephritis & 0 & 1 & 0 & 9 & 10 \\
\hline HSP nephritis & 0 & 0 & 0 & 4 & 4 \\
\hline $\begin{array}{l}\text { Mesangioproliferative } \\
\text { glomerulonephritis }\end{array}$ & 0 & 3 & 0 & 0 & 3 \\
\hline Crescentic glomerulonephritis & 0 & 0 & 2 & 0 & 2 \\
\hline $\begin{array}{l}\text { Membranoproliferative } \\
\text { glomerulonephritis }\end{array}$ & 0 & 1 & 0 & 0 & 1 \\
\hline Minimal change disease & 0 & 1 & 0 & 0 & 1 \\
\hline Normal histology & 1 & 0 & 0 & 0 & 1 \\
\hline Total & 8 & 20 & 6 & 13 & 47 \\
\hline
\end{tabular}

on basis of low c3 complement level, raised Antistreptolysin $\mathrm{O}$ and or AntiDNase B titer. Two children had low c3, c4 complement levels and negative ANA. Remaining 8 children had normal complement levels.

Out of 6 children with clinical presentation of AGN, gross hematuria, hypertension and edema with rapidly deteriorating renal functions, two children were suggestive of PSGN, one child had positive p-antineutrophil cytoplasmic antibody ( $\mathrm{p}$-ANCA) and rest three did not have identifiable etiology at the onset. Among these 6 children, 5 required hemodialysis. There were two children with PSGN who had rapidly deteriorating renal functions of which one did not require renal replacement therapy and another had to undergo hemodialysis. One child with ANCA positive vasculitis, one with IgA nephropathy and one with pauciimmune crescentic glomerulonephritis remained dialysis dependent even after three months of treatment.

Nine $(12.5 \%)$ children had active urinary sediments along with hypocomplementemia, positive ANA and Anti dsDNA; of which two children had malar rash suggestive of SLE and underwent for renal biopsy. Similarly four (5.6\%) children had features of nephritis along with palpable purpura and arthritis and/or abdominal pain suggestive of HSP.

Among 8 (11.1\%) children who underwent for renal biopsy for gross hematuria, 7 had recurrent gross hematuria and 1 patient had features of AGN without features of poststreptococcal glomerulonephritis.

Fifty seven children (79.1\%) had primary glomerular disease and secondary glomerular disease accounted in 24 children. One child who underwent renal biopsy had unremarkable glomerular morphology in light microscopy and immunofluorescence. IgA nephropathy, minimal change disease, FSGS, diffuse proliferative glomerulonephritis and lupus nephritis were the common histopathological findings.
Other histological findings are as shown in Figure 1.

Histological diagnosis of FSGS was observed in 3 $(37.5 \%)$ out of 8 children with SRNS and $3(42.8 \%)$ out of 7 children with nephrotic syndrome along with atypical features. Majority of children with SDNS had minimal change disease in renal histology (Table 2). FSGS was predominantly observed in age group $11-18$ years $(50 \%)$ which was followed by in age group $1-5$ years $(37.5 \%)$ (Table 3).

Histopathological findings as per different indications for renal biopsy other than nephrotic syndrome is shown in Table 4. Majority of children (6 out of 7) with recurrent gross hematuria had IgA nephropathy in renal biopsy and one child had normal histology in light microscopy and immunofluorescence study. Similarly out of 8 children presenting with mixed nephritic-nephrotic features with normal complement levels, 6 had histopathological features of IgA nephropathy. Most of IgA nephropathy children $(73.3 \%)$ were in $11-18$ years age group (Table 3 ).

All the six children with clinical presentation of AGN with rapidly deteriorating renal functions had crescents in glomeruli in renal histopathology (4 had crescents in 53 to $86 \%$ of glomeruli and remaining 2 patients had 10 to $18 \%$ of glomeruli with crescents). Among four children with crescents involving more than $50 \%$ of glomeruli, features of lupus nephritis, IgA nephropathy, p-ANCA positive vasculitis and pauci-immune crescentic glomerulonephritis was present in one child each.

Diffuse proliferative glomerulonephritis (DPGN) was observed in children aged above 5 years only with majority in age group of 11 to 18 years. Out of 12 children with DPGN, 10 had features of PSGN who had persistent nephrotic range proteinuria, one child had features of AGN without features suggestive of PSGN and one child had 
Table 5. Correlation of crescents in glomeruli with histopathological diagnosis

\begin{tabular}{|c|c|c|c|c|c|c|c|}
\hline $\begin{array}{l}\text { Adequacy of } \\
\text { sample }\end{array}$ & $\begin{array}{l}\text { Proportion of } \\
\text { glomeruli with } \\
\text { crescents }\end{array}$ & $\begin{array}{c}\text { IgA } \\
\text { nephropathy }\end{array}$ & $\begin{array}{l}\text { Diffuse proliferative } \\
\text { glomerulonephritis }\end{array}$ & $\begin{array}{c}\text { Crescentic } \\
\text { glomerulonephritis }\end{array}$ & $\begin{array}{c}\text { Lupus } \\
\text { nephritis }\end{array}$ & $\begin{array}{c}\text { HSP } \\
\text { nephritis }\end{array}$ & Total \\
\hline Glomeruli <10 & Crescents $\geq 25 \%$ & 0 & 1 & 0 & 0 & 1 & 2 \\
\hline \multirow{2}{*}{ Glomeruli $\geq 10$} & Crescents $<25 \%$ & 4 & 5 & 0 & 2 & 1 & 12 \\
\hline & Crescents $\geq 25 \%$ & 1 & 0 & 2 & 2 & 1 & 6 \\
\hline Total & & 5 & 6 & 2 & 4 & 3 & 20 \\
\hline
\end{tabular}

AGN with rapidly deteriorating renal functions requiring renal replacement therapy. Six patients had crescents and one child who required hemodialysis had crescents in $42 \%$ of glomeruli.

There were altogether 10 patients with lupus nephritis out of which 7 had diffuse proliferative lupus nephritis class IV and 3 had focal lupus nephritis class III histological features. One child fulfilled criteria for crescentic glomerulonephritis. Majority of children with lupus nephritis were observed in 11 to 18 years age group and female gender.

HSP nephritis was observed in four children, all of whom were in age range of 10-13 years. Three patient of HSP nephritis had crescents ( 2 had crescents in $>25 \%$ glomeruli) (Table 5).

On light microscopy, crescents were seen in $20(27.8 \%)$ children. Only one child with crescent was observed in biopsy specimen with $<10$ glomeruli. Twelve out of total 20 children had $<25 \%$ crescents with predominance in diffuse proliferative glomerulonephritis (5/12) and IgA nephropathy (4/12) among biopsies with glomeruli $\geq 10$ (Table 5). More than $25 \%$ crescents were observed in lupus nephritis $(2 / 6)$ and crescentic glomerulonephritis (2/6).

\section{DISCUSSION}

Renal biopsy is an invasive but safe procedure that is required for the diagnosis and management of various clinical spectrum of renal diseases in children. ${ }^{9}$ Renal biopsy in children is done with extreme caution after adequate preparation and all precautions are taken to obtain good tissue samples with minimal risk of complications and discomfort to the child. Failure rate of $5.3 \%$ was observed in this study as compared to 2.3 to $11.8 \%$ in other studies. $3,4,10$ Similarly the complications noted were minimal which were similar to previous studies ${ }^{2,3,10}$ and were appropriately managed.

The most common reason for renal biopsy in children was nephrotic syndrome which was consistent with previous studies. ${ }^{4,11,12}$ Primary glomerular disease predominated the histopathological lesions among renal biopsy in children as in previous studies. ${ }^{3,6}$ However, the histopathological pattern differ widely in various studies..$^{2-7}$

Unlike the previous study from $\mathrm{Nepal}^{2}$, IgA nephropathy was the commonest histopathological finding in this study, however the proportions of IgA nephropathy were comparable. Similarly various other studies from East Asia

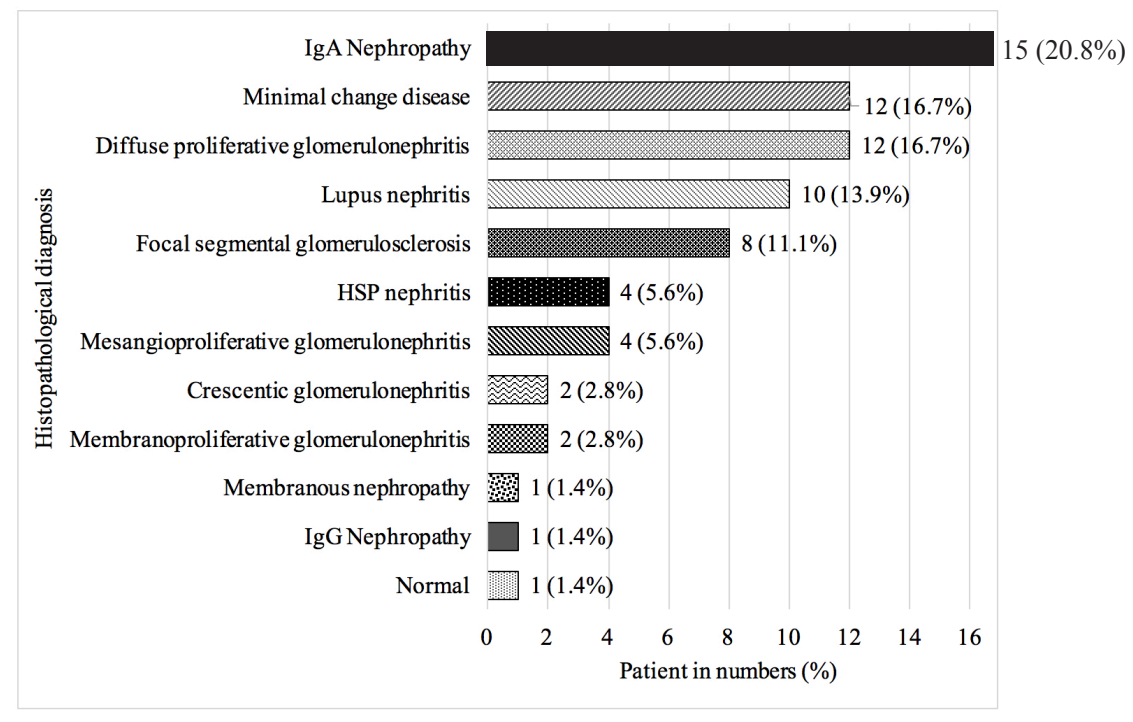

Figure 1 : Histopathological diagnosis and its frequency 
and Europe showed IgA nephropathy as the most frequent histopathological diagnosis among renal biopsies. ${ }^{6,11,13}$ Few other studies from Morocco and Egypt showed lower rates of IgA nephropathy which was as low as $3.4 \%$ of all biopsies. ${ }^{4}, 14$ This may indicate toward racial predisposition and geographical variation. Previous study among Nepalese children showed IgA nephropathy in $17.2 \%$ of biopsies which were exclusively observed in age group of 10 to 14 years $^{2}$ whereas $71.4 \%$ of children with IgA nephropathy were in age group of 10 to 18 years and was also observed in younger age group in this study. IgA nephropathy was the commonest histopathological diagnosis among children presenting with recurrent gross hematuria which was consistent with other study. ${ }^{3}$ In one patient with recurrent gross hematuria, biopsy findings were non diagnostic. Previous study has shown inability to confirm diagnosis by renal biopsy in 2 out of 13 patients with recurrent gross hematuria. $^{3}$

Minimal change disease was the second commonest histopathological diagnosis in this study and the commonest in cohort of children with nephrotic syndrome. Other studies have also shown most frequent occurrence of minimal change disease among children who underwent renal biopsy $y^{4,15}$ as compared to focal segmental glomerulosclerosis as the most frequent observation another studies., ${ }^{2,3,5,7}$ Most of children with SDNS had minimal change disease. This differed in patients with SRNS where FSGS appearance predominated which was also noted in a study among Indian children. ${ }^{16}$

Membranous glomerulonephritis has been shown to constitute from 5 to $10 \%$ of renal biopsies in children ${ }^{10}$ as compared to $1.4 \%$ in this study. These variations may indicate difference in spectrum of glomerular disease in various geographical location or racial or selection bias of studies.

Crescentic glomerulonephritis is severe form of glomerulonephritis and occurs as $1.6-5.5 \%$ of biopsies. ${ }^{14,17}$ In this study, two children (2.8\%) had crescentic glomerulonephritis and both remained dialysis dependent. All the children with AGN with rapidly deteriorating renal functions had crescents in renal biopsy, but only $66.7 \%$ of patients fulfilled criteria of crescentic glomerulonephritis (i.e. crescents in more than $50 \%$ of glomeruli). ${ }^{18}$

DPGN was observed in $16.7 \%$ patients as compared to $15.3 \%$ and $27.7 \%$ of biopsies in a study from Egypt and Jamaica respectively. ${ }^{14,19}$ PSGN was the major cause of DPGN seen in $75 \%$ of children. ${ }^{19}$ Majority of children with PSGN do not require renal biopsy. However those who have persistent nephrotic range proteinuria and /or persistent gross hematuria or rapidly deteriorating renal functions need to undergo renal biopsy. In our study $83.3 \%$ of children with DPGN had PSGN supported by clinical presentation of AGN, low c3 and positive Antistreptolysin $\mathrm{O}$ and/or AntiDNase B titers. Five (41.7\%) out of 12 children with PSGN had crescents; and one with rapidly deteriorating renal functions had $42 \%$ of glomerulus with crescents on biopsy and required hemodialysis. Higher proportion of DPGN attributable to PSGN in this study may be explained because of occurrence of PSGN as high as one-third of children with renal disorders in a Nepalese study. ${ }^{1}$ This may be related to prevalent referral practices as most complicated cases are the ones referred to tertiary care center where the study was conducted. There was high rates of proliferative glomerulonephritis of $12.6 \%$ in 1991 and decreased by $4.1 \%$ in 2008 in Turkey ${ }^{5}$ and lower rates of postinfectious glomerulonephritis in Greece $^{3}$ relating to improved hygiene and early treatment facilities.

Lupus nephritis and HSP nephritis were the most common secondary glomerular diseases in our study which is consistent with previous studies. ${ }^{5,6,10}$ Only $13.9 \%$ of children showed lupus nephritis in this study in contrast to $27.6 \%$ in previous study among Nepalese children. ${ }^{2} 37.8 \%$ children had diffuse proliferative lupus nephritis ${ }^{2}$ as compared to $70 \%$ of children with diffuse proliferative lupus nephritis class IV in this study. HSP nephritis was observed in 5.6\% as compared to $6.9 \%$ in a Nepalese study ${ }^{2}$ and $6.3 \%$ in another study. ${ }^{4}$

The major limitation of study was its retrospective study design. The study was conducted at two tertiary care centers which were referral centers for complicated renal disorders causing selection bias. Hence the results may not represent the true occurrence of renal pathology in community. Renal biopsy might not have been possible in few children fulfilling indications for renal biopsy due to parental reluctancy or financial constraints which might have affected the actual results. Electron microscopy study which is now considered an essential component to describe glomerular pathology was lacking in this study.

\section{CONCLUSION}

Renal biopsy is vital for diagnosis of renal disease in children. It is safe and can be done effectively even with limited resources. Nephrotic syndrome was the commonest indication for renal biopsy and most of them were found to have minimal change disease. Those children with nephrotic syndrome who underwent renal biopsy for being steroid resistant or for falling in older age group were more likely to have FSGS. Overall, IgA nephropathy was the commonest histopathological diagnosis. IgA nephropathy was most likely to be found in children who presented with recurrent gross hematuria and those who presented with mixed nephritic-nephrotic feature. Lupus nephritis was the commonest secondary glomerular disease observed.

\section{Conflict of interest: None}




\section{REFERENCES}

1. Yadav S, Shah G, Mishra O, Baral N. Pattern of renal diseases in children: A developing country experience. Saudi J Kidney Dis Transpl. 2016;27:371-6. Crossref

2. Khatun N, Bista KP, Mahaseth C. Spectrum of biopsy proven glomerular disease in children at Kanti Children's Hospital. Journal of Nepal Paediatric Society. 2014;34:225-9.

3. Printza N, Bosdou J, Pantzaki A, Badouraki M, Kollios K, Ghogha $\mathrm{C}$, et al. Percutaneous ultrasound-guided renal biopsy in children: a single centre experience. Hippokratia. 2011;15:258-61. $\underline{\text { Crossref }}$

4. Souilmi FZ, Houssaini TS, Alaoui H, Harmouch T, Atmani S, Hida $\mathrm{M}$. Indications and results of renal biopsy in children: A single-center experience from Morocco. Saudi J Kidney Dis Transpl. 2015;26:8105. Crossref

5. Fidan K, Isik Gonul I, Büyükkaragöz B, Isiyel E, Arinsoy T, Soylemezoglu O. Changing trends in pediatric renal biopsies: analysis of pediatric renal biopsies in national nephrology registry data. Renal Failure. 2016;38:1228-33. Crossref

6. Lee SA, Kim MS, Kim SC, Lee D-Y. Clinical and pathological findings of renal biopsy in children: Outcomes from a single center over 27 years. Child Kidney Dis. 2017;21:8-14. Crossref

7. Paripovic D, Kostic M, Kruscic D, et al. Indications and results of renal biopsy in children: a 10-year review from a single center in Serbia. J Nephrol. 2012;25:1054-9. 당s

8. Bagga A, Ali U, Banerjee S, et al. Management of steroid sensitive nephrotic syndrome: revised guidelines. Indian J Pediatr. 2008;45:203-14. $\underline{\text { Crossref }}$

9. Visconti L, Cernaro V, Ricciardi CA, et al. Renal biopsy: Still a landmark for the nephrologist. World J Nephrol. 2016;5:321-7. $\underline{\text { Crossref }}$

10. Ozkayin N, Ciplak G, Usta U, Genchellac H, Temizoz O. Assessment of ten-year-long results of kidney biopsies performed on children in the Thrace region of Turkey. Balkan Med J.2016;33:589-93. Crossref
11. Carvalho E, do Sameiro Faria M, Nunes JP, Sampaio S, Valbuena C. Renal diseases: a 27-year renal biopsy study. J Nephrol. 2006;19:5007. $\underline{\text { Crossref }}$

12. Imtiaz S, Nasir K, Drohlia MF, Salman B, Ahmad A. Frequency of kidney diseases and clinical indications of pediatric renal biopsy: A single center experience. Indian J. Nephrol. 2016;26:199-205. $\underline{\text { Crossref }}$

13. Zheng $\mathrm{Y}, \mathrm{Xu} \mathrm{H}$, Zhou L, et al. Clinicopathological features of paediatric renal biopsies in Shanghai over a 31 year period. Nephrol(Carlton). 2012;17:274-7. Crossref

14. Bakr A, Eid R, Sarhan A, et al. Fifteen years of kidney biopsies in children: A single center in Egypt. Saudi J Kidney Dis Transpl. 2014;25:1321-7. Crossref

15. Lanewala A, Mubarak M, Akhter F, Aziz S, Bhatti S, Kazi JI. Pattern of pediatric renal disease observed in native renal biopsies in Pakistan. J Nephrol. 2009;22:739-46. Crossref

16. Gulati S, Sengupta D, Sharma RK, et al. Steroid resistant nephrotic syndrome: role of histopathology. Indian J Pediatr.2006;43:55-60.

17. Choudhury T, Singh R, Usha et al. Clinicopathologic spectrum of crescentic glomerulonephritis: A hospital-based study. Saudi J Kidney Dis Transpl. 2014;25:689-96. Crossref

18. Jennette JC. Rapidly progressive crescentic glomerulonephritis. Kidney Int. 2003;63:1164-77. Crossref

19. Miller M, Gooden M, Shah D, Soyibo A, Williams J, Barton E. Renal biopsy findings in Jamaican children. West Indian Med J. 2010;59:325-9. Crossref 